\title{
Membrane-associated DNA Transport Machines
}

\author{
Briana Burton ${ }^{1}$ and David Dubnau ${ }^{2}$ \\ ${ }^{1}$ Department of Molecular and Cellular Biology, Harvard University, Cambridge, Massachusetts \\ ${ }^{2}$ Public Health Research Center, New Jersey Medical School, University of Medicine and Dentistry of \\ New Jersey, Newark, New Jersey \\ Correspondence:dubnauda@umdnj.edu
}

DNA pumps play important roles in bacteria during cell division and during the transfer of genetic material by conjugation and transformation. The FtsK/SpollIE proteins carry out the translocation of double-stranded DNA to ensure complete chromosome segregation during cell division. In contrast, the complex molecular machines that mediate conjugation and genetic transformation drive the transport of single stranded DNA. The transformation machine also processes this internalized DNA and mediates its recombination with the resident chromosome during and after uptake, whereas the conjugation apparatus processes DNA before transfer. This article reviews these three types of DNA pumps, with attention to what is understood of their molecular mechanisms, their energetics and their cellular localizations.

$\mathrm{T}_{\mathrm{b}}^{\mathrm{h}}$ he transport of DNA across membranes by bacteria occurs during sporulation, during cytokinesis, directly from other cells and from the environment. This review addresses the question "how is the DNA polyanion transferred processively across the hydrophobic membrane barrier"?

DNA transport must occur through waterfilled channels, at least conceptually addressing the problem posed by the hydrophobic membrane. DNA transporters presumably use metabolic energy directly or a coupled-flow (symporter or antiporter) mechanism to drive DNA processively through the channel. It is possible that a Brownian ratchet mechanism, in which directionality is imposed on a diffusive process, also contributes to transport.
In this article, we will consider several DNA transport systems. We will begin with the simplest one, namely the FtsK/SpoIIIE system that is involved in cell division and sporulation. We will then turn to the more complex, multiprotein DNA uptake systems that accomplish genetic transformation (the uptake of environmental DNA from the environment) and the conjugation systems of Gram-negative bacteria that mediate the unidirectional transfer of DNA between cells. In each case we will discuss the proteins involved, their actions and the sources of energy that drive transport. Space limitations prevent discussion of other relevant topics, such as DNA transport during bacteriophage infection and more than a brief reference to conjugation in Gram-positive bacteria.

Editors: Lucy Shapiro and Richard Losick

Additional Perspectives on Cell Biology of Bacteria available at www.cshperspectives.org

Copyright (C) 2010 Cold Spring Harbor Laboratory Press; all rights reserved; doi: 10.1101/cshperspect.a000406

Cite this article as Cold Spring Harb Perspect Biol 2010;2:a000406 


\section{CELL DIVISION AND SPORULATION}

\section{General Features of DNA Transport in Cell Division}

Proper chromosome segregation is essential for successful cell division, and yet under rapid growth conditions bacterial cells can form a division septum before completion of DNA segregation. To accomplish this, the cells have dedicated proteins of the FtsK/SpoIIIE family that move the remainder of the chromosome into the appropriate daughter-cell compartment. Given that a single gene product codes for all the transport functionality, this is the simplest DNA transport system discussed here.

The simplicity of the single polypeptide chain belies the fact that these transporters function in the division septum, one of the most topologically challenging environments of the bacterial cell. When chromosomes have not fully segregated into daughter compartments, the constricting septal membranes constitute an obstacle for the final resolution of the cellular genetic material. In many of the bacteria that contain FtsK/SpoIIIE proteins, the chromosomes are circular molecules. This means that any portion of the chromosome that is on the wrong side of the division plane will have a loop of dsDNA that must first be resolved properly from its sister chromosome, and second be moved in the correct direction across the division plane.

Information about the FtsK/SpoIIIE family of transporters is derived largely from the work on two founding members of the protein family. FtsK from Escherichia coli has yielded much functional information about the role of these proteins in terminus resolution during chromosome segregation (a more detailed account of its recombination function may be found in Thanbichler 2009). SpoIIIE, which has a specialized function during the asymmetric division of sporulating Bacillus subtilis cells, has produced complementary information about these transporters. The focus of this section is on how the ATPases of the FtsK/SpoIIIE protein family transport chromosomal DNA in the context of cellular division membranes.

\section{The FtsK/SpolIIE Proteins}

The FtsK/SpoIIIE family of DNA transporters is conserved among the bacteria (Iyer et al. 2004). Proteins of the FtsK/SpoIIIE family have diverse functions including the export of virulence factors, conjugative transfer of plasmid DNA and chromosome partitioning. Those members involved in chromosome partitioning share a functional domain called $\gamma$ (discussed later) (Wang et al. 2006; Ausmees et al. 2007; Le Bourgeois et al. 2007; Wang et al. 2007; Val et al. 2008; Dedrick et al. 2009) and have the distinction of functioning at a unique interface within cells- the constricting division plane.

Until recently, it was thought that all chromosomal transporters in this family harbor amino-terminal transmembrane domains. New studies on a SpoIIIE paralog in B. subtilis have prompted a revision of the group to include soluble FtsK proteins. Interestingly, all of these FtsK/SpoIIIE proteins localize to cell division membranes, and they do so only at the time of division (Wu and Errington 1997; Biller and Burkholder 2009; Kaimer et al. 2009). The newly characterized soluble protein, $\mathrm{Sft}$, localizes to predivisional sites, presumably through direct protein-protein interactions with FtsZ, rather than through membrane tethering (Biller and Burkholder 2009). FtsK localizes to vegetative cell division septa, as does SpoIIIE, although the latter does so rarely $(\mathrm{Wu}$ and Errington 1997; Wang and Lutkenhaus 1998; Yu et al. 1998). In the case of sporulation, SpoIIIE localization requires the presence of DNA in the septal plane (Ben-Yehuda et al. 2003). The presence of FtsK at division planes is enhanced under conditions that produce an increased number of bisected nucleoids ( $\mathrm{Yu}$ et al. 1998). The amino-terminal transmembrane segments of both proteins are required for proper septal localization (Begg et al. 1995; Draper et al. 1998; Yu et al. 1998; Sharp and Pogliano 1999) and although there is little sequence conservation in this region, the transmembrane segments appear to mediate interaction with and recruitment of other division machinery proteins (Di Lallo et al. 2003). Furthermore, the transmembrane domains are 
required for proper function of SpoIIIE (Sharp and Pogliano 2003), although the precise role of the FtsK transmembrane domains for DNA transport activity is still unknown.

Little is understood about the precise role of the variable length linker domain that follows the transmembrane segments. However studies in E. coli using domain deletions and chimeras with the Haemophilus influenzae FtsK show that the linker portion of the protein does play a role in proper cell division (Bigot et al. 2004). The absence of the linker domain correlates with increased filamentation in these strains, and this phenotype could be functionally separated from a previously characterized role for the linker in chromosome dimer resolution (Aussel et al. 2002).

The carboxy-terminal regions of these proteins contain the conserved portions of the proteins including the ATPase motifs and the directionality determining gamma domain. $\operatorname{TrwB}$, a conjugation protein from the plasmid R388, provided the first structural insights into the ATPase domain of this protein family (Gomis-Ruth et al. 2001). The structure of the soluble domain of TrwB (lacking the aminoterminal transmembrane region) revealed two domains. First, an NBD similar to RecA and ring helicases, and second a domain entirely composed of $\alpha$-helices. A solution structure of the soluble ATPase domain of FtsK confirmed the presence of a RecA-like fold, but also revealed a unique jawlike domain connected to the RecA fold (Massey et al. 2006). Comparison of two crystal forms suggests a hinge-like movement between the two domains that could lead to a rotary-inchworm translocation mechanism. The structural studies also showed that FtsK has a large central pore, about $25 \AA$ in diameter that could accommodate a dsDNA molecule (Massey et al. 2006). In contrast, TrwB which may transport ssDNA (see later), has a smaller, 8 Å diameter, central pore (Gomis-Ruth et al. 2001).

The soluble ATPase domains of both SpoIIIE and FtsK have been shown to translocate along double stranded DNA in an ATP dependent manner (Bath et al. 2000). In fact, in both cases, the ATPase activity is dependent on the presence of double stranded DNA. In
Membrane-associated DNA Transport Machines

single-molecule experiments, FtsK produced an average translocation rate of $\sim 5 \mathrm{~Kb} / \mathrm{s}$ (Saleh et al. 2004; Pease et al. 2005). EM of the FtsK motor domain in the presence of doublestranded DNA suggest that a hexamer of the protein forms rings around the DNA (Aussel et al. 2002; Massey et al. 2006). Further evidence that these rings are hexamers comes from size exclusion chromatography where the soluble domain of FtsK migrates as a hexamer(Aussel et al. 2002).

Recent studies have focused on SftA, the soluble FtsK/SpoIIIE-like DNA translocase from B. subtilis mentioned earlier (Biller and Burkholder 2009; Kaimer et al. 2009). In contrast to SpoIIIE, which assembles at late stages of cell division, SftA assembles at nascent division septa with FtsZ and before membrane scission (Biller and Burkholder 2009) (Fig. 1a). $\mathrm{SftA}$ is required for chromosome partitioning early in cell division, in part through increased chromosome dimer resolution, thus making it more similar to FtsK in terms of its role in chromosome segregation. SpoIIIE, on the other hand, serves as a back-up mechanism for completing chromosome segregation postseptationally (Biller and Burkholder 2009; Kaimer et al. 2009). Interestingly, some bacterial species such as clostridia carry only a single $\gamma$ domaincontaining paralog. Those with two FtsK/ SpoIIIE ATPases containing $\gamma$ domains, cluster in the low GC-Gram-positive bacteria, $\alpha$ proteobacteria, and $\beta$-proteobacteria (Biller and Burkholder 2009). Many of these organisms are naturally closely linked to soil and plants but are not endospore formers, suggesting that the presence of the SpoIIIE-like back-up protein is not tightly correlated with spore formation.

A remarkable feature of these chromosome transporters is their ability to move the DNA in the appropriate direction with astounding accuracy. This ability depends on sequence motifs in the chromosomal DNA (Bigot et al. 2005; Levy et al. 2005; Pease et al. 2005; Ptacin et al. 2008; Biller and Burkholder 2009). Short eight-nucleotide sequences, known as KOPS and SRS sequences for FtsK- and SpoIIIErecognition respectively, are overrepresented on the plus strand of the chromosome and are recognized by the $\gamma$ domain on the very 


\section{B. Burton and D. Dubnau}

A

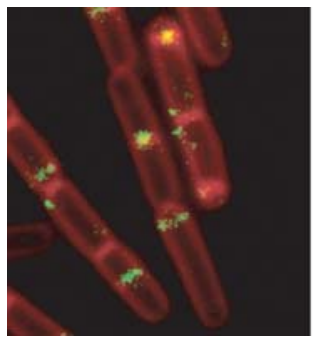

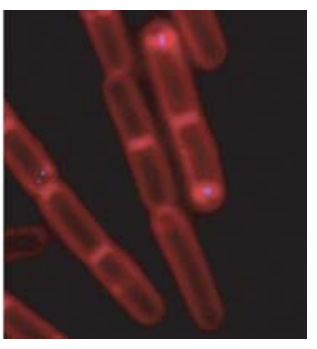

B

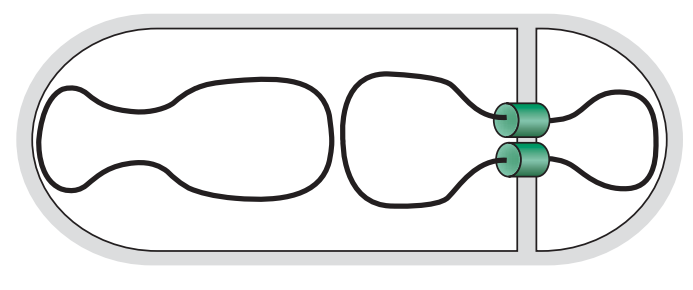

Figure 1. Localization of chromosome segregation proteins, SftA and SpoIIIE, in Bacillus subtilis. (A) SftA localizes to early division septa in B. subtilis, whereas SpoIIIE localizes late in division and largely sporulation septa. This image shows fluorescence overlayed from FM4-64 membrane-staining (red), a SftAYFP fusion (green) and a SpoIIIE-CFP fusion (blue), of cells from a sporulating culture. SftA fluorescence is apparent at predivisional and vegetative divsion sites, whereas SpoIIIE fluorescence colocalizes with fully formed sporulation division membranes. (Images courtesy of J. Liu.) (B) Schematic of the chromosome crossing the division septum through two independent DNA-conducting channels formed by SpoIIIE in a sporulating B. subtilis cell. At the end of the transport process, the final loop of DNA in the large compartment must be resolved across the division plane, by an as yet undetermined mechanism.

carboxyl terminus of the FtsK/SpoIIIE proteins. This domain recognizes these sequences and uses them as a guide to accurately move the chromosome into the appropriate daughter cell (Ptacin et al. 2006; Sivanathan et al. 2006). The co-crystal structure of three $\gamma$ domains bound to KOPS sequence DNA provides structural support for biochemical experiments, suggesting that KOPS DNA establishes directional DNA translocation through oriented protein loading (Bigot et al. 2006; Lowe et al. 2008). Further cytological and functional evidence suggests that SpoIIIE follows this same oriented loading paradigm (Sharp and Pogliano 2002a; Sharp and Pogliano 2002b; Becker and Pogliano 2007; Ptacin et al. 2008).

Although these insights have helped to answer the major conundrum in the field regarding how the FtsK/SpoIIIE proteins faithfully segregate chromosomal material into the correct daughter cell, a lingering question remains: How do the proteins resolve loops of DNA at the division plane? In bacteria with circular chromosomes, it is predicted based on the pore size of the ATPase domain, that each independent hexameric transporter will encompass one double stranded "arm" of the chromosome (Fig. 1B). For the proteins that act predivisionally, such as SftA and presumably
FtsK, the scenario is relatively simple to imagine. A small loop of DNA remains on the "wrong" side of the division plane, and when the transporters reach the loop, they might disengage the DNA. This release would allow the loop of DNA to move into the appropriate daughter cell through simple Brownian motion facilitated by the act of chromosome organization and compaction on the daughter cell side. In contrast, the resolution of a loop in a postseptational system, such as that of SpoIIIE, must involve one of two possible mechanisms (Becker and Pogliano 2007; Burton et al. 2007). One possibility is that the chromosomal DNA is linearized and rejoined after transport. Another is that a rearrangement of the proteins to form a single, larger channel could allow the loop to move across the septum uncleaved. Lateral opening of the channels could be driven by the mechanical force that the loop of DNA exerts on the two hexameric complexes. This sort of mechanism is appealing because it would allow for resolution of any DNA loop caught in the septal space, not just the last loop near the chromosome terminus. Further studies on the link between directional transport and the ultimate resolution of local DNA structures at the division plane will be needed to address this issue. 


\section{B. subtilis Sporulation as Model System}

B. subtilis SpoIIIE, is required for active transport of chromosomal DNA during B. subtilis sporulation (Wu and Errington 1998). During sporulation, B. subtilis cells divide asymmetrically, creating a larger mother cell and a smaller forespore. Two-thirds of the chromosome destined for the spore compartment remains on the mother cell side of the newly formed septum, and must be actively transported into the spore ( $\mathrm{Wu}$ and Errington 1998). Cells lacking SpoIIIE are unable to move the chromosome into the spore compartment, and are therefore completely defective for sporulation (Wu and Errington 1994). Similarly cells specifically defective for SpoIIIE ATPase activity are unable to complete the sporulation program (Sharp and Pogliano 2002b).

SpoIIIE is expressed in vegetative cells and is distributed uniformly throughout the membrane (Foulger and Errington 1989). During sporulation, SpoIIIE protein levels do not change. However, at the onset of sporulation, SpoIIIE moves to the septum, localizing to the midpoint of the converging lipid bilayers ( $\mathrm{Wu}$ and Errington 1997). The generation of this SpoIIIE focus requires the presence of DNA in the septal annulus (Ben-Yehuda et al. 2003). The SpoIIIE focus remains at the septum until the entire chromosome has moved into the forespore (Sharp and Pogliano 2003). Interestingly, SpoIIIE has been implicated in a second function during sporulation, apparently unrelated to chromosome transport. After transport is complete, the protein relocalizes to the pole of the sporulating cell, where it plays an additional role in fusing the membranes of the mother cell engulfing the prespore (Sharp and Pogliano 1999).

What about the proteins that normally decorate a chromosome? Fluorescence microscopy experiments provided evidence that not only are the FtsK/SpoIIIE proteins efficient movers of DNA, they also have the ability to remove virtually every protein roadblock in their way, leaving the transported DNA to enter the daughter cell naked (Marquis et al. 2008). The case of sporulation, where over three megabases of DNA are transported to the daughter cell, highlights this best as transcription factors, chromosome
Membrane-associated DNA Transport Machines

compaction proteins, and other site-specifically bound proteins, are all removed during DNA transport (Marquis et al. 2008). How exactly these translocases accomplish such a daunting task remains to be determined.

\section{Protein-Protein Interactions}

The most striking feature of the FtsK/SpoIIIE proteins is that despite their complex functions, the actual DNA transport activity is seemingly accomplished entirely by these proteins. Whereas the next nucleic acids transporter systems to be discussed, competence and transformation, are composed of numerous gene products, FtsK and SpoIIIE appear to function entirely on their own. Nevertheless, it remains to be seen whether there are still other accessory proteins to be discovered that play a role in the DNA transport activity, or whether these proteins really function as lone powerhouses for their chromosome transport function.

\section{CONJUGATION}

\section{General Features of Gram-Negative Conjugation Systems}

Conjugation refers to the transfer of DNA from one cell to another, by a process requiring cellcell contact. As with transformation, the transferred molecule is ssDNA. Conjugation and Type 4 protein secretion are mediated by similar complex machines, which in at least some cases mediate the transfer of both DNA and protein substrates. Conjugation involves the participation of pilins, but these are different from the Type 4 pilins needed for transformation. Our discussion will emphasize the Agrobacterium tumefaciens system that transfers DNA into plant cells and the E. coli R388 plasmid conjugation system. For more detailed descriptions of conjugation, the reader is referred to recent reviews (Chen et al. 2005; Christie et al. 2005; Chandran et al. 2009).

\section{The Conjugation Proteins}

The core proteins required for DNA transfer during conjugation are usually divided for 


\section{B. Burton and D. Dubnau}

convenience into two groups; the DNA processing and transfer (DTR) and the mating pair formation (MPF) proteins. DTR proteins process the DNA to be transferred and resemble the proteins needed for rolling circle replication by bacteriophage $\Phi X 174$ and by certain plasmids. It has been proposed that the MPF proteins are needed to form a pilus that connects the donor and recipient cells, retracting to bring the cell surfaces into more intimate contact (Panicker and Minkley 1985). Recent evidence suggests that at least in the case of the F-pilus, single stranded DNA may travel through the pilus, into the recipient cell (Babic et al. 2008; Shu et al. 2008). However, the role of pili in conjugation is not clear and some Type 4 secretion systems appear to lack them. MPF proteins are also needed to form structures that traverse the inner membrane, the periplasm and the outer membrane, forming a channel for the passage of DNA. In the conjugation systems, a Type 4 coupling (T4C) protein mediates interaction between ssDNA produced by the DTR proteins and the MPF apparatus.

\section{DTR and Coupling Proteins}

Among the R388 DTR proteins are the relaxase/ helicase TrwC, the host IHF protein and TrwA, which also functions as a transcriptional repressor of the $d t r$ genes. These proteins form the relaxosome, which binds to the oriT region of the super-coiled plasmid DNA (Christie 1997; Gomis-Ruth and Coll 2006). TrwC nicks one strand and covalently attaches by its catalytic tyrosine residue to the $5^{\prime}$ end of the strand destined for transfer. The helicase activity of TrwC then unwinds the DNA and DNA polymerase III replaces the transferred strand by rolling circle replication. The IHF and TrwA components of the relaxosome probably play architectural roles, shaping the DNA into a conformation that favors TrwC binding and activity. The covalently attached $\operatorname{TrwC}$ then acts as a "pilot protein" accompanying the T-DNAprotein complex into the recipient cell.

Although recognition by the DNA transfer machinery requires motifs present on the relaxase, rather than a specific DNA sequence, this is not a mere protein secretion system, with DNA coming along for the ride. The length of the transferred strand demands that active DNA transport must take place. The Type 4 coupling (T4CP) protein (TrwB from R388 and VirD4 from A. tumefaciens) assembles into a hexamer and has an amino-terminal membrane-embedded domain on each protomer, as well as a large cytosolic moiety. The structure of this moiety has been solved and consists of two domains, a nucleotide-binding domain distal to the membrane surface and a membraneproximal $\alpha$-helical domain (Gomis-Ruth et al. 2001). Running through the cytosolic moiety is a central channel that is $\sim 20 \AA$ wide in TrwB but decreases to $\sim 8 \AA$ at the cytosolic extremity. It is not known if this channel continues through the membrane domain and accommodates the ssDNA during transfer, because the structure was derived from a truncated derivative lacking the membrane-embedded moiety. The narrow entrance at the cytoplasmic end may carry out a gating function as transfer is initiated. Aside from its suggestive structure and cellular location, several other attributes support the role of TrwB as a DNA pump. For instance, TrwB is a DNA-dependent ATPase, and shows conformational changes in the surface residues of the central channel depending on its ATP-binding state (Tato et al. 2005). In addition, the closest structural analog to TrwB is stated to be FtsK, although the latter protein has a wider central channel, presumably to allow the passage of dsDNA. It is worth noting that members of the HerA/FtsK/SpoIIIE protein family are also required for conjugation in Gram-positive bacteria (Iyer et al. 2004; Berkman et al. 2010) The nucleotide-binding domain of TrwB also resembles that of the ring helicases, which are known to use the energy of ATP hydrolysis to translocate along DNA (Gomis-Ruth et al. 2001).

\section{MPF Proteins}

The MPF proteins are numerous, 11 in the case of A. tumefaciens where they are best characterized (Christie et al. 2005; Fronzes et al. 2009a). In addition to the proteins that assemble 
the pilus (VirB2 and VirB5) additional proteins (VirB4, VirB6, VirB7, VirB8, VirB9, and VirB10) assemble across the bacterial envelope. Biochemical investigation established that VirB8, VirB10, and the NTPase VirB4, are anchored in the inner membrane, VirB9 is located in either the periplasm or in association with the outer membrane, and VirB7 is probably associated with the outer membrane. These proteins presumably establish a channel extending from the T4CP protein (VirD4) to the exterior surface. The VirB11 ATPase is recruited to the inner face of the inner membrane where it is needed for the assembly of the secretion channel. This proposed role for VirB11, in mediating assembly of a trans-envelope structure perhaps containing a pilus subunit, is analogous to that proposed for the secretion ATPases of the T4 pilus-related systems (see later), and in fact VirB11 has been classified as a secretion (or traffic) ATPase. In addition to VirD4 and VirB11, VirB4 is also an ATPase and together these three proteins, which contact one another, presumably power the assembly of the conjugation nano-machine as well as secretion of DNA.

The role of the pilin proteins is unclear. A filamentous structure composed of pilin subunits, perhaps a mini- or pseudopilus, may be an obligatory part of the conjugation machinery, even providing a channel for DNA transport. Another possibility is that pilin subunits may assemble with MPF proteins to form a transport structure whereas pili per se may be an alternative structure, requiring the MPF proteins for its formation.

Recently, two major advances have contributed to an enhanced understanding of these complex systems. The first is the so-called transfer DNA immunoprecipitation (TrIP) assay. This technique, based on cross-linking of DNA to proteins using immunoprecipitation and PCR, has identified proteins that are proximal to the DNA during transport (Cascales and Christie 2004). This has established a provisional transport pathway and has suggested the identity of channel subunits. As expected, VirD4 is the first protein contacted by the DNA following interaction with the relaxosome. Next the DNA contacts the VirB11 ATPase and
Membrane-associated DNA Transport Machines

this interaction depends on the presence of other core components, but not on the Walker A and B residues of VirB11. Why VirB11 interacts with DNA is unknown, but it may have a direct role during transport, aside from its morphogenetic role in building the core. In two subsequent steps, close contacts are established between the DNA and VirB6 and VirB8, located in the inner membrane, and then with the outer membrane/periplasmic VirB2 pilin and with VirB9. These valuable findings constrain model building, based on the second major advance, the acquisition of high-resolution structural data.

Although several individual component structures had been solved (Yeo et al. 2000; Yeo et al. 2003; Terradot et al. 2005; Bayliss et al. 2007), a big step forward derives from the $15-\AA$-resolution cryoelectron microscopy structure of a complex between the VirB7VirB9-VirB10 orthologs from the plasmid pK101 (TraN, TraO, and TraF respectively) (Fronzes et al. 2009b). This $1.05 \mathrm{MDa}$ "core complex" is composed of 14 copies of each protein, forming a double-walled two-chambered channel, proposed to span both membranes. The inner and outer chambers contain a channel that extends $105 \AA$, sufficient to bridge the two membranes. The channel is open on the cytoplasmic side and constricted near the other end. The outer surface of the structure is composed mostly of TraF/VirB10, whereas TraN/ VirB7 and TraO/VirB9 form the inner wall of the channel. It is suggested that the orthologs of the VirB4 and VirB11 ATPases may regulate the opening at the distal end, communicating across the inner membrane and periplasm by some unknown mechanism, permitting passage of the DNA. This beautiful structure provides no explicit role for these ATPases, the T4C protein, or for the orthologs of VirB2, VirB6, and VirB8. Presumably one or more of these proteins decorates the outside of the structure, interacts with it within the membrane or may even be located in one of the large chambers.

More recently, the remarkable crystal structure of a 0.6 MDa fragment of this core structure, derived from chymotrypsin treatment, has been reported (Chandran et al. 2009). This structure corresponds to the outer chamber 


\section{B. Burton and D. Dubnau}

of the cryo-EM structure. Unexpectedly, the VirB10 protein, which crosses the inner membrane, also comprises the outer membrane channel. It may thus represent the first bacterial protein that traverses both membranes. Figure 2 shows the crystal structure of the outer membrane complex superimposed on the cryo-EM structure. Detailed comparison of the two structures reveals suggestive differences, which may reflect conformational changes underlying DNA transport (Chandran et al. 2009). It has been suggested that the large chambers may be sites of assembly of the MPF proteins not represented in the core structure, and that these may form the actual channel for substrate transport (Chandran et al. 2009; Christie 2009). Naturally many questions remain concerning the detailed mechanisms of secretion and the energetics of the process. One wonders if the showed requirement for the VirB2 pilin for transport hints at a dynamic role for a pilus, or for a pseudopilus, analogous to that proposed below for the competence pseudopilus? The mechanism by which the DNA is transported into the recipient cell is also obscure, although a role for a pilus has

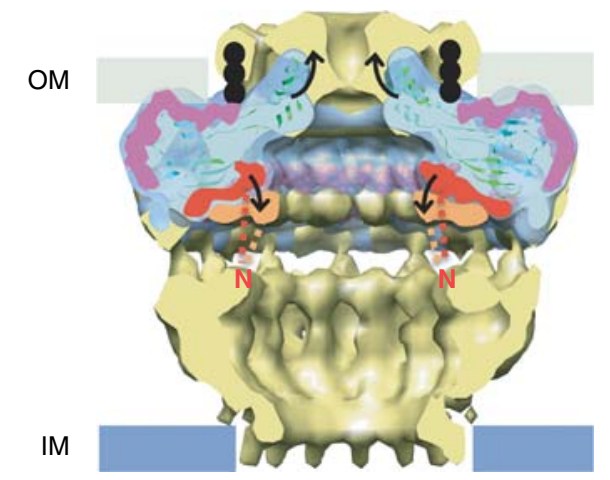

Figure 2. Proposed structure of the core complex for T4S system ( $\mathrm{pKM101)-mediated} \mathrm{conjugation.} \mathrm{The}$ cryo-EM structure (yellow) is superimposed on the crystal structure of the outer-membrane complex. The location of lipid associated with TraN/VirB7 is shown with black dots. The arrows illustrate proposed conformational changes (Chandran et al. 2009). OM and IM indicate outer and inner membrane, respectively. (Adapted, with permission, from Chandran et al. 2009 [(C) Nature Publishing Group].) been suggested (Backert et al. 2008). Although these and other major questions are unresolved, the VirB7-9-10 structure represents a breakthrough that should lead to rapid advances in understanding.

\section{TRANSFORMATION}

\section{General Features of Bacterial Transformation}

Transformation refers to the transport of environmental DNA to the cytosolic compartment, where it can meet several fates. If the incoming DNA is complementary to the resident chromosome, it can recombine. If it contains the information needed for independent replication, it can do so as a plasmid or a bacteriophage. As with conjugation, the transported DNA is single-stranded. The nontransforming strand is degraded, most likely by a mechanism that is closely connected to transport across the cell membrane (Mejean and Claverys 1993).

These shared features reflect the existence of a common set of transformation proteins (Dubnau 1999). Gram-positive and Gramnegative bacteria share the core proteins, except that the latter group has additional components enabling DNA to cross the outer membrane. Among these conserved transformation proteins are those that are needed for Type 4 pili (T4P) and Type 2 secretion (T2S). Helicobacter pylori is unusual because it uses a conjugation-like system for DNA transport, rather than the usual shared transformation proteins (Hofreuter et al. 2000).

In most bacteria, complex signal transduction pathways regulate the proteins that mediate DNA uptake (Macfadyen 2000; Hamoen et al. 2003; Claverys et al. 2006; Leisner et al. 2008). Cells that synthesize these transformation proteins are referred to as "competent." Although the core transformation proteins are mostly conserved, the regulatory mechanisms are not. This is a common theme; nature often uses a common set of tools, but uses species-specific instructions for their use. We will not further describe the regulation of competence gene expression. This article reflects the bias of the authors by emphasizing the B. subtilis system, 
although information from other bacteria will be included when needed. The B. subtilis nomenclature for proteins and genes will be used throughout. Several reviews are available that emphasize transformation in other bacteria or that offer more detail (Berge et al. 2002; Friedrich et al. 2002; Hamilton and Dillard 2006; Claverys et al. 2009).

\section{The Fate of Transforming DNA}

It is useful to follow a DNA molecule from its existence in solution outside the cell, until it becomes integrated in the resident genome of the transformant (reviewed in Berge et al. 2002; Chen and Dubnau 2004; Chen et al. 2005). Double stranded DNA (dsDNA) first binds to the $B$. subtilis cell surface without sequence specificity and is then fragmented by the action of a membrane-localized nuclease (NucA) that presumably acts at the points of attachment (Provvedi et al. 2001). After binding and fragmentation, one strand is degraded, releasing phosphorylated products into the medium and the transforming strand is converted into a form that is no longer accessible to added DNAse. DNAse resistance is taken as an indication of transport across the cell membrane. Indeed no difference in the kinetics of appearance of transformants, DNAase resistance and degradation products has been detected. In S. pneumoniae, the transforming strand is taken up with $3^{\prime}$ to $5^{\prime}$ polarity and the nontransforming strand is degraded with $5^{\prime}$ to $3^{\prime}$ polarity, consistent with close coordination of the degradation and uptake steps (Méjean and Claverys 1988; Mejean and Claverys 1993). (For a possible difference in B. subtilis, see Vagner et al. 1990.) 3' ssDNA termini initiate recombination in all systems and in the case of transformation, the uptake mechanism itself generates this required substrate. Internalized ssDNA thus interacts with the resident chromosome and RecA-mediated recombination results in formation of a heteroduplex in which one strand is from the donor and the other from the recipient chromosome. This heteroduplex molecule is at first stabilized by non-covalent bonds, after which ligation
Membrane-associated DNA Transport Machines

occurs. The heteroduplex is resolved by replication and in S. pneumoniae by mismatch repair as well (Claverys and Lacks 1986; Majewski and Cohan 1998).

In Gram-negative bacteria, e.g., H. influenzae and Neisseria gonorrhoeae, dsDNA presumably passes across the outer membrane through ring-shaped assemblies of proteins known as secretins (Tomb et al. 1991; Collins et al. 2004). It has been reported that the secretin complex of $N$. gonorrhoeae contains the initial binding site for DNA during transformation (Assalkhou et al. 2007). On entry to the periplasm, DNA is thought to become resistant to exogenously added DNAse. Transport into the cytosol is more difficult to detect in Gram-negative bacteria and "uptake" is (operationally) defined differently than in the Gram-positives. In Haemophilus and Neisseria, specific sequences are required for efficient transformation (Danner et al. 1980; Elkins et al. 1991), but the receptor for this sequence is unknown. More typically, DNA uptake shows no discernible sequence specificity.

Single molecule experiments (Maier et al. 2004) have shown that DNA uptake in B. subtilis is processive, with no detectable pausing at a temporal resolution down to $1 \mathrm{~s}$. Uptake was observed to occur at a rate of about $80 \mathrm{bp} / \mathrm{s}$. (A similar rate of $(\sim 90 \mathrm{bp} / \mathrm{s})$ has been estimated for S. pneumococus (Mejean and Claverys 1993)). Uptake remained processive and its velocity was invariant against large external forces, up to $\sim 40 \mathrm{pN}$. These measurements establish both the DNA transformation motor and the FtsK/SpoIIIE motors as uniquely powerful. They also set the parameters that must be explained by any proposed mechanism.

\section{The Transformation Proteins}

In B. subtilis and S. pneumoniae, several cytosolic proteins under competence-specific control are required for optimal transformation; RecA, SsbB (YwpH), DprA (Smf) and YjbF (CoiA) (reviewed in Claverys et al. 2009). RecA is required for integration of transforming DNA and in its absence, little or no transformation for chromosomal markers is detected, 
although transformation by plasmid DNA proceeds normally. When the competence-specific ssDNA binding proteins SsbB or DprA are absent, incoming DNA is degraded (Berge et al. 2003). DprA appears to play a role in loading RecA onto ssDNA to form RecA filaments, preparatory to recombination (Mortier-Barriere et al. 2007). The molecular role of YjbF is obscure. Inactivation of any one of these cytosolic proteins decreases transformation, but does not prevent the uptake of transforming DNA, measured by the DNAse resistance of radiolabeled DNA. Nevertheless, it is possible that they do play a role in transport, perhaps by binding to incoming ssDNA, thereby preventing backward slippage. Consequently, their absence may affect the rate or processivity of uptake.

Two membrane proteins are needed for the appearance of DNAse resistant radiolabeled DNA but are not required for binding of DNA to the cell. One of these, ComEC, is a large polytopic transmembrane protein, which is likely to form at least part of the pore for DNA uptake (Draskovic and Dubnau 2005). In B. subtilis, inactivation of comEC prevents not only uptake of DNA, but also the degradation of the nontransforming strand. In contrast, degradation proceeds normally in the equivalent $S$. pneumoniae mutant (Berge et al. 2002). In S. pneumoniae, a membrane endonuclease (EndA) has been shown to be required for nontransforming strand degradation (Lacks et al. 1974). The endA gene is not under competence control and no ortholog of endA exists in B. subtilis. These observations suggest an important difference in the coupling of DNA uptake and degradation in the two bacteria. Another membraneassociated protein, ComFA, possesses the conserved motifs typical of Super family 2 helicase/translocases and is also needed for DNA uptake but not for DNA binding. Mutation of the ComFA Walker A motif completely inactivates the protein for uptake (LondonoVallejo and Dubnau 1994) and ComFA may therefore contribute energetically to DNA uptake by translocation or may mediate strand separation before degradation of the nontransforming strand. These are attractive ideas, because a membrane-anchored translocase could drive DNA into the cell and particularly because Super family 2 proteins can track along a single strand and do so mostly with $3^{\prime}$ to $5^{\prime}$ polarity (Singleton et al. 2007). A null mutant of a third membrane protein, ComEA, does not internalize DNA and was reported to reduce binding to the cell surface, measured by incubation with radiolabeled DNA followed by centrifugal washing (Inamine and Dubnau 1995). ComEA possesses two helix-loop-helix motifs near its carboxyl terminus, and is inserted in the membrane with these motifs located externally. Such motifs are known to bind DNA nonspecifically, and indeed the corresponding part of ComEA binds dsDNA (Provvedi and Dubnau 1999). An in-frame deletion of a central portion of ComEA, has a minor effect on DNA binding, but eliminates uptake. Apparently, although the dsDNA binding activity of ComEA is essential, ComEA is also needed for transport.

An important group of proteins essential for transformation is related to Type 4 pilus (Craig et al. 2004) and Type 2 secretion (T2S) proteins (Johnson et al. 2006) of Gram-negative bacteria (Albano et al. 1989; Hobbs and Mattick 1993). Type 4 pili (T4P) are filamentous helical assemblies of pilin proteins that emerge through a secretin pore in the outer membrane. The assembly and disassembly of the T4P drives twitching motility (Merz et al. 2000; Skerker and Berg 2001; Burrows 2005). By analogy, it has been proposed that cycles of assembly and disassembly of a "pseudopilus" provide the mechanical force for T2S through a secretin pore and for the uptake of DNA during transformation (Mattick 2002). A T2S pseudopilus has been characterized (Skerker and Berg 2001; Kohler et al. 2004), but no direct evidence for its cyclical assembly and disassembly has been presented.

Typically, the T4P, T2S and competence systems encode several pilin or pseudopilin proteins, which contain conserved, hydrophobic, $\alpha$-helical domains that traverse the membrane (Sauvonnet et al. 2000; Mattick 2002; Burrows 2005; Chen et al. 2005; Proft and Baker 2009). These systems also require dedicated, membrane-localized proteases, a conserved polytopic integral membrane protein, and at 
least one hexameric, P-loop "traffic ATPase" that is peripherally associated with the inner face of the cell membrane. This class of ATPases is commonly associated with processes that involve the transport of macromolecules and is a subclass of AAA+ proteins. Traffic ATPases are required for formation of the pili and pseudopili. After removal of several amino-terminal amino acid residues from the pilin proteins by the dedicated protease, the mature pilins are translocated from the membrane to the periplasm/wall and the T4P or Type 2 pseudopili are assembled so that the hydrophobic $\alpha$-helices of the (pseudo)pilins are buried in the interfaces between the subunits of these structures (Forest and Tainer 1997; Craig et al. 2004).

This general picture applies in the case of B. subtilis and almost certainly the other transformation systems. The B. subtilis orthologs of $\mathrm{T} 4 \mathrm{P}$ and T2S genes are encoded by $\operatorname{com} C$ (the protease) and by the com $G$ operon (reviewed in Chen and Dubnau 2004). This operon contains seven genes, encoding the secretion ATPase (ComGA), the conserved polytopic membrane protein (ComGB) and four typical pseudopilins. Thus all the core components of these systems are present and a competence pseudopilus, composed of the major pseudopilin, ComGC, has been described (Chen et al. 2006). Immediately after synthesis, ComGC is located as an integral membrane protein with its carboxyl terminus extending outward from the membrane (Chung et al. 1998). The competence-specific thiol oxido-reductase proteins, $\mathrm{BdbD}$ and $\mathrm{BdbC}$ then oxidize the two cysteine residues of ComGC to form an intramolecular disulfide bond, and cleavage by ComC takes place (Fig. 3A). The processed ComGC is then translocated to a location outside the membrane, and the competence pseudopilus is assembled (Chen et al. 2006). In addition to $\operatorname{com} C$ and $b d b D C$, each of the com $G$ ORFs are required for formation of the pseudopilus. This structure is asymmetric and highly polydisperse. Remarkably, the ComGC subunits are held together not only by noncovalent interactions, but also by intermolecular disulfide bonds, which presumably form by exchange with the pre-existing intramolecular
Membrane-associated DNA Transport Machines

S-S bonds. The average length of the competence pseudopilus is apparently sufficient to cross the cell wall of B. subtilis. (It is interesting that in other, unrelated pili of Gram-positive bacteria, the subunits are covalently linked by isopeptide bonds (Mandlik et al. 2008)).

FRET measurements and microscopic colocalization studies on fluorescent fusion proteins have shown that many of the competence proteins are in contact or in close proximity (Hahn et al. 2005; Kidane and Graumann 2005; Kramer et al. 2007; Tadesse and Graumann 2007). Even the cytosolic ("soluble") proteins are in intimate association with the membrane components of the transformation apparatus. Specifically, ComFA, ComEA, ComGA, SsbB, YjbF, DprA, and RecA have been shown to colocalize at the poles of $B$. subtilis (Fig. 4). This colocalization is dynamic, at least for DprA and RecA (Kidane and Graumann 2005; Tadesse and Graumann 2007). DNA binding takes place preferentially at the poles, close to foci of competence protein concentrations, and less often near laterally located foci, which are helically distributed. Single molecule experiments indicate that DNA uptake, like binding, also occurs preferentially at or near the cell poles (Hahn et al. 2005). These studies show that the transformation proteins function in concert and that a multicomponent protein machine carries out transformation, from the initial binding step all the way to integration.

Given the striking similarities of the proteins involved in transformation, T4P and T2S, the filamentous structures they form and the requirement in each system for movement (of DNA, a cell, and protein respectively), it is attractive to consider that a mechanism like the one that powers twitching motility also drives DNA uptake for transformation. In fact, T4Plike proteins are required for transformation in every system that has been studied, both Gram-negative and -positive, with the exception of Helicobacter pylori (see later). The single molecule DNA uptake studies show that the force-velocity characteristics of DNA uptake are similar to those of $\mathrm{T} 4 \mathrm{P}$ retraction; both are processive and operate with constant velocity 


\section{B. Burton and D. Dubnau}

A

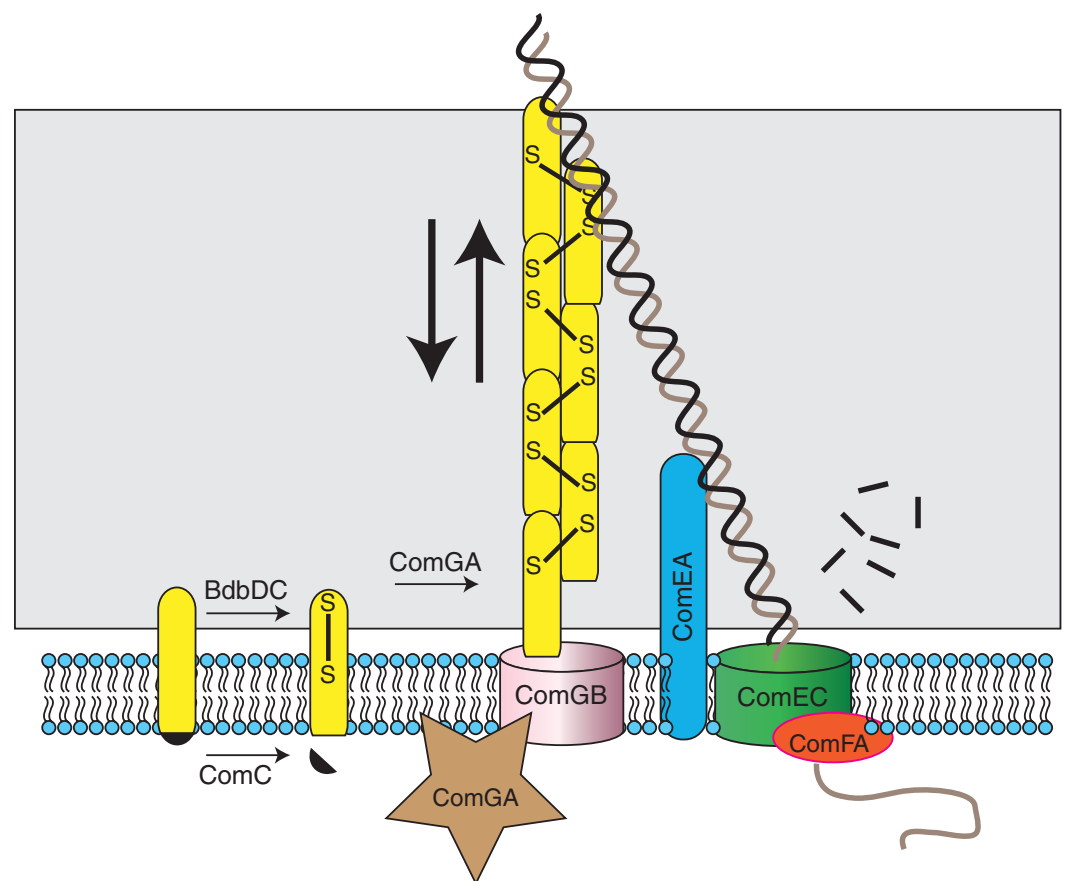

B

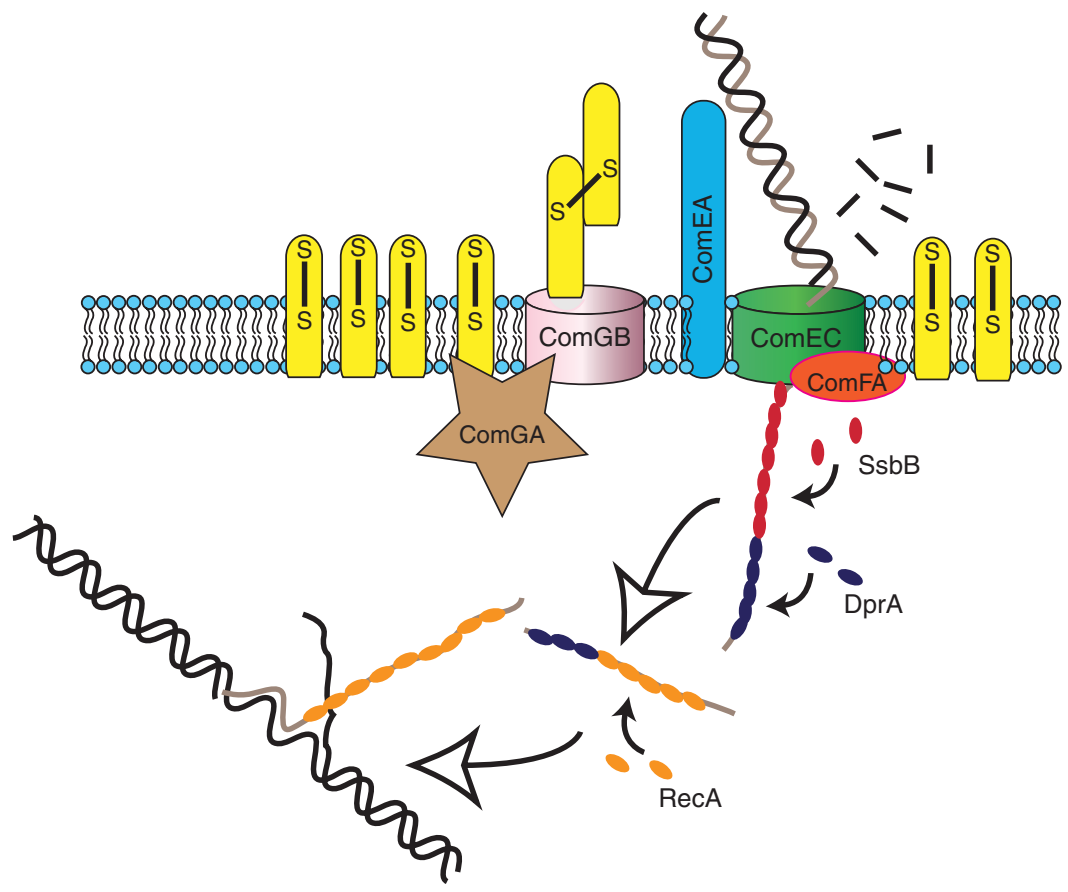

Figure 3. A model for transformation in Gram positive bacteria. ComGC is processed by the protease ComC and oxidized to form an intramolecular disulfide bond by BdbDC. (A) It is then translocated from the membrane in a step that requires the traffic ATPase ComGA and assembled into a pseudopilus in which the intramolecular disulfide bonds are replaced by links between the subunits. ComGB is represented at the base of the pseudopilus without direct evidence. It is proposed that assembly and disassembly of the pseudopilus brings transforming DNA to the ComEC channel and that interaction of the DNA with the C-terminal part of 


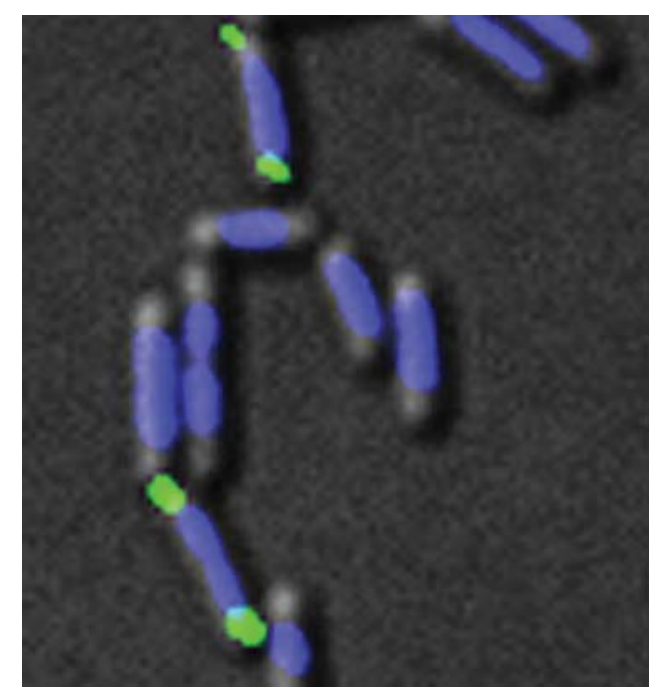

Figure 4. ComGA-GFP localizes to the poles of competent B. subtilis. This image shows fluorescence from DAPI-staining (blue), and a ComGA-GFP fusion (green), overlayed on a DIC image of ten cells from a competent culture. Two competent cells are present, in both of which the ComGA fluorescence is localized near the cell poles. (Photo courtesy of J. Hahn.)

against relatively high loads (Maier et al. 2002; Maier et al. 2004). No direct evidence yet exists demonstrating a role for pseudopilus assembly and disassembly in DNA transport, but evidence from analysis of com $G A$ point mutations has shown that the ATPase ComGA, and probably the pseudopilus, are needed for transport (K. Briley and D. Dubnau, unpublished). ComGA, but not the pseudopilus, is also needed for DNA binding to the cell. Because ComGA is located on the inner surface of the membrane, the ComGA requirement for competencespecific DNA binding suggests that this protein
Membrane-associated DNA Transport Machines

communicates across the membrane with an unidentified DNA receptor. This receptor is not ComEA, and in fact when a filtration technique rather than the more disruptive centrifugal washing measures binding of radiolabeled DNA, inactivation of comEA has very little effect on total DNA bound. It is likely that DNA binding takes place first to the unknown receptor and to ComEA at a later step.

\section{The Transformation Model}

The following model for the transformation process is consistent with the available evidence (Fig. 3). dsDNA first binds to an unknown receptor that communicates with ComGA. The DNA is cleaved by the membrane nuclease NucA, providing an end for the initiation of transport through a pore formed at least in part by ComEC. The pseudopilus then drives uptake by cycles of assembly and disassembly. The highly processive nature of uptake requires either the participation of several pseudopili acting in concert, or of another DNA binding protein that prevents the DNA from slipping backwards through the pore. ComEA is an attractive candidate for this role. An unknown nuclease in B. subtilis (EndA in the case of S. pneumoniae) degrades one strand during transport, and ComFA may unwind the DNA before this degradation step and/or may provide part of the driving force for uptake after degradation. Following transport, ssDNA is protected by binding to SsbB and DprA and also interacts with RecA. Because the core competence proteins are conserved in (nearly) all transformation systems, the essential features of this model are likely to be universal. An alternative view, compatible with the evidence, is

Figure 3. (Continued) ComEA is required for uptake, which is assisted by the ATPase ComFA. The transforming strand (gray) enters the cytosol and the nontransforming strand is degraded with the products exiting the cell. The nomenclature is that of B. subtilis. In S. pneumoniae, EndA (not shown) carries out degradation of the non-transforming strand. Also not shown is NucA, which introduces double strand breaks in the bound DNA. The large gray square represents cell wall material. (B) The pseudopilus has disassembled and the ComGC subunits have returned to the membrane where they may form a pool available for further cycles of assembly/disassembly. As the ssDNA enters the cytosol, it interacts with SsbB and DprA. These proteins protect the DNA and DprA also assists in loading RecA to form a filament, which is proposed to carry out the homology search leading to recombination with the resident chromosome 


\section{B. Burton and D. Dubnau}

that the pseudopilus functions to bring the DNA across the cell wall and periplasm, into contact with the membrane-localized proteins that then mediate transport to the cytosol. In this view, transformation would be a two-step process.

The cellular locations of DprA and RecA vary during transformation (Kidane and Graumann 2005; Tadesse and Graumann 2007). DprA, which shows only occasional polar localization before transformation, becomes dramatically localized to the poles when DNA is added. In contrast, RecA departs from the poles when DNA is added, forming filaments that then diffuse rapidly. A reasonable hypothesis is that ssDNA engages $S s b B$ at the ComEC pores, which serves to protect the DNA and aid assembly of ssDNA-DprA complexes. ssDNA thus acts to localize DprA near the cell poles, although protein - protein contacts probably also participate. DprA assists in the loading of RecA on the ssDNA (Mortier-Barriere et al. 2007), forming filaments, which then show dynamic behavior, conducting a diffusive search for sites of homology on the chromosome. Thus, a picture is emerging of a transformation machine, with moving parts that mediate not only the binding and uptake of DNA, but also the interaction of ssDNA with the resident chromosome. This coordinated action of DNA uptake and recombination proteins constitutes strong evidence that transformation has evolved for the acquisition of genetic information.

What are the sources of energy for uptake? Older experiments with inhibitors indicate a role for the $\mathrm{pH}$ component of proton motive force (PMF) (van Nieuwenhoven et al. 1982; Bremer et al. 1984). Consistent with this is the demonstration in single DNA molecule experiments that uncouplers (DNP and CCCP) arrest uptake well before the ATP pool is depleted (Maier et al. 2004), suggesting that a proton symport mechanism may drive transport. However, it is fully possible that ATP also plays a direct role consistent with the essentiality of the Walker A motif of the helicase-like ComFA protein for uptake (Londono-Vallejo and Dubnau 1994).
In the T4P systems, there are two traffic ATPases, one of which appears to drive assembly and the other disassembly of the pilus (Herdendorf et al. 2002; Burrows 2005; Chiang et al. 2008; Jakovljevic et al. 2008). However, the competence and T2S systems each possess single known ATPases, which more closely resemble the assembly ATPases of T4P. Perhaps PMF directly disassembles the pseudopili or the single ATPase can operate in reverse. Recent laser tweezer analyses of T4P retraction in N. gonorrhoeae and Myxococcus xanthus have revealed the presence of two retraction motors; a high-force, low-velocity motor dependent on the retraction ATPase, PilT and a high-velocity, low-force motor that is PilT-independent (at least in M. xanthus) (Clausen et al. 2009a; Clausen et al. 2009b). The stalling force of the high velocity motor $(70 \mathrm{pN})$ is suggestive of the B. subtilis DNA uptake system, in which measurements hinted at a stalling force somewhat in excess of $40 \mathrm{pN}$ (Maier et al. 2004). These findings are consistent with a mode of competence pseudopilus retraction that is not dependent on a traffic ATPase, perhaps driven instead by PMF.

\section{Other Dynamic Aspects of \\ the Transformation Machine}

During the development of competence in B. subtilis, many of the relevant proteins accumulate at the poles of the cells and in foci that appear to be helically distributed in association with the cell membrane. More or less concomitantly with a loss of transformability, these proteins leave the poles (Hahn et al. 2005). Time-lapse microscopy and the use of inhibitors suggest that movement to the poles depends on diffusion, with capture at the poles by an anchoring site (Hahn et al. 2009). In contrast, departure from the poles is energy-driven, and depends on the action of the proteins McsA and $\mathrm{B}$. McsA and B are known to act together as adaptors for the ClpCP and ClpEP proteases (Kirstein et al. 2007) and inactivation of these degradative proteins (McsA, McsB, ClpP, or of $\mathrm{ClpC}+\mathrm{ClpE}$ ) prevents delocalization of competence proteins. It is postulated that the 
degradative complexes degrade an anchor protein, releasing the competence proteins and in agreement with this, McsB, ClpC, and $\mathrm{ClpP}$ move to the poles of competent cells (Hahn et al. 2009). The localization and delocalization of competence proteins is clearly regulated, but there is no information as to the signaling pathways involved. It is also not known why assembly of the transformation machinery and DNA uptake occur at the poles. Perhaps localization favors low affinity assembly interactions, and the poles simply provide a convenient address. Alternatively, unique properties of the wall/ membrane at the poles facilitate assembly and insertion of the competence machine.

\section{Transformation in Helicobacter pylori}

The Helicobacter transformation system is a unique case in which core inner membrane and cytosolic constituents (notably the channel protein ComEC and $d p r A$ ) are conserved (Ando et al. 1999; Smeets et al. 2000; Yeh et al. 2003) whereas the T4P-like proteins are replaced by conjugation proteins, encoded by the comB2-B4 and comB6-B10 operons (Karnholz et al. 2006). Helicobacter is therefore a hybrid between the more common transformation systems and the conjugation machines.

An instructive recent paper (Stingl et al. 2010) shows that the comB operons of Helicobacter mediates high velocity, low-force uptake of double stranded DNA into the periplasm, whereas comEC is needed for transport of single stranded DNA into the cytosol, presumably by a high-force mechanism akin to that used by B. subtilis. This study has at least two important implications. First, it is the clearest demonstration that transformation in Gram-negative bacteria is a two-step process, with uptake into the periplasm temporally uncoupled from transport into the cytosol. Second, it implies that the T4P-like and the conjugation-like transformation proteins play analogous roles, conveying double stranded DNA into the periplasm and across the cell wall to provide accessibility of this DNA to the conserved inner membrane transport apparatus. This view of competence is similar to that proposed above for the roles
Membrane-associated DNA Transport Machines

of the pseudopilus and membrane proteins in B. subtilis.

\section{COMPARISON OF THE CONJUGATION, TRANSFORMATION AND FTSK/SPOIIIE SYSTEMS: UNANSWERED QUESTIONS}

The conjugation and transformation systems use ssDNA as substrate and require the assembly of elaborate machines composed of several proteins, including those that span the cell envelope. In both systems cytosolic proteins process the DNA substrate either before transfer or following import and in both, these proteins interact with and coordinate their activities with the membrane transporters. Another striking similarity between these systems is the involvement of pilus-like structures. However, given our present state of knowledge, the resemblance between these systems ends here, because there is little obvious similarity between the conjugation and transformation proteins, other than the prominent involvement of P-loop NTPases. It is likely that this reflects our ignorance and that analogous roles for individual proteins will become apparent.

Because of this ignorance, many questions remain unanswered. Among the most important unresolved issues are the following. What are the immediate sources of energy driving the movement of DNA across the membrane(s)? What proteins does the DNA contact, particularly during transformation, and at what stages during transport? Is assembly and disassembly of a pilus-like structures involved in transport? In the Gram-negative transformation and conjugation systems, is there a role for pili per se in the transport process, or do the pilus proteins assemble into alternative DNA-transport specific structures? Finally, what is the meaning of the positioning at the cell poles of not only transformation, but also of the conjugation proteins of some bacteria (Judd et al. 2005; Teng et al. 2008; Berkman et al. 2010). Clearly structural information on the component proteins will contribute in a major way to our understanding. In the case of transformation, the interactions of transport and recombination 


\section{B. Burton and D. Dubnau}

proteins, analogous to those of the DTR proteins and membrane components of the conjugation apparatus, continue to be of major interest.

The FtsK system, whereas functionally quite distinct from the conjugation and transformation machinery, does share the central and defining role of the P-loop ATPase activity, and in fact as mentioned earlier, several conjugation proteins are members of the HerA/FtsK family. In contrast to conjugation and transformation, the FtsK/SpoIIIE proteins use dsDNA as a substrate, and the barrier across which FtsK/ SpoIIIE translocates the DNA is variable. Thus, whereas ostensibly a more simple system than the multicomponent machineries of conjugation and transformation, the current state of knowledge about FtsK and SpoIIIE raise several challenging mechanistic questions. For example, how are loops of DNA resolved? How do these proteins clear other DNA binding proteins away from the transported DNA so rapidly and effectively? And ultimately, what is the architecture of these complexes in the context of the cell division machinery and septal membranes? These questions continue to fuel inquiry from many angles.

\section{ACKNOWLEDGMENTS}

Work cited from the BB lab was supported by a Massachusetts Life Science Center Grant, and from the DD lab by National Institutes of Health grants GM057720 and GM043756.

\section{REFERENCES}

Albano M, Breitling R, Dubnau DA. 1989. Nucleotide sequence and genetic organization of the Bacillus subtilis com $G$ operon. J Bacteriol 171: 5386-5404.

Ando T, Israel DA, Kusugami K, Blaser MJ. 1999. HP0333, a member of the dprA family, is involved in natural transformation in Helicobacter pylori. J Bacteriol 181: 5572-5580.

Assalkhou R, Balasingham S, Collins RF, Frye SA, Davidsen T, Benam AV, Bjoras M, Derrick JP, Tonjum T. 2007. The outer membrane secretin PilQ from Neisseria meningitidis binds DNA. Microbiology 153: 1593-1603.

Ausmees N, Wahlstedt H, Bagchi S, Elliot MA, Buttner MJ Flardh K. 2007. SmeA, a small membrane protein with multiple functions in Streptomyces sporulation including targeting of a SpoIIIE/FtsK-like protein to cell division septa. Mol Microbiol 65: 1458-1473.

Aussel L, Barre FX, Aroyo M, Stasiak A, Stasiak AZ, Sherratt D. 2002. FtsK Is a DNA motor protein that activates chromosome dimer resolution by switching the catalytic state of the XerC and XerD recombinases. Cell 108: 195-205.

Babic A, Lindner AB, Vulic M, Stewart EJ, Radman M. 2008. Direct visualization of horizontal gene transfer. Science 319: $1533-1536$.

Backert S, Fronzes R, Waksman G. 2008. VirB2 and VirB5 proteins: Specialized adhesins in bacterial type-IV secretion systems? Trends Microbiol 16: 409-413.

Bath J, Wu LJ, Errington J, Wang JC. 2000. Role of Bacillus subtilis SpoIIIE in DNA transport across the mother cell-prespore division septum. Science 290: 995-997.

Bayliss R, Harris R, Coutte L, Monier A, Fronzes R, Christie PJ, Driscoll PC, Waksman G. 2007. NMR structure of a complex between the VirB9/VirB7 interaction domains of the pKM101 type IV secretion system. Proc Natl Acad Sci 104: 1673-1678.

Becker EC, Pogliano K. 2007. Cell-specific SpoIIIE assembly and DNA translocation polarity are dictated by chromosome orientation. Mol Microbiol 66: 1066-1079.

Begg KJ, Dewar SJ, Donachie WD. 1995. A new Escherichia coli cell division gene, ftsK. J Bacteriol 177: 6211-6222.

Ben-Yehuda S, Rudner DZ, Losick R. 2003. Assembly of the SpoIIIE DNA translocase depends on chromosome trapping in Bacillus subtilis. Curr Biol 13: 2196-2200.

Berge M, Mortier-Barriere I, Martin B, Claverys JP. 2003. Transformation of Streptococcus pneumoniae relies on DprA- and RecA-dependent protection of incoming DNA single strands. Mol Microbiol 50: 527-536.

Berge M, Moscoso M, Prudhomme M, Martin B, Claverys JP. 2002. Uptake of transforming DNA in Gram-positive bacteria: A view from Streptococcus pneumoniae. Mol Microbiol 45: 411-421.

Berkman MB, Lee CA, Loveday E-K, Grossman AD. 2010. Polar positioning of a conjugation protein from the integrative and conjugative element ICEBs1 of Bacillus subtilis. J Bacteriol 192: 38-45.

Bigot S, Corre J, Louarn JM, Cornet F, Barre FX. 2004. FtsK activities in Xer recombination DNA mobilization and cell division involve overlapping and separate domains of the protein. Mol Microbiol 54: 876-886.

Bigot S, Saleh OA, Cornet F, Allemand JF, Barre FX. 2006. Oriented loading of FtsK on KOPS. Nat Struct Mol Biol 13: $1026-1028$.

Bigot S, Saleh OA, Lesterlin C, Pages C, El Karoui M, Dennis C, Grigoriev M, Allemand JF, Barre FX, Cornet F. 2005. KOPS: DNA motifs that control E. coli chromosome segregation by orienting the FtsK translocase. Embo J 24: 3770-3780.

Biller SJ, Burkholder WF. 2009. The Bacillus subtilis SftA (YtpS) and SpoIIIE DNA translocases play distinct roles in growing cells to ensure faithful chromosome partitioning. Mol Microbiol 74: 790-809.

Bremer W, Kooistra J, Hellingwerf KJ, Konings WN. 1984. Role of the electrochemical proton gradient in genetic transformation of Haemophilus influenzae. J Bacteriol 157: $868-873$. 
Burrows LL. 2005. Weapons of mass retraction. Mol Microbiol 57: 878-888.

Burton BM, Marquis KA, Sullivan NL, Rapoport TA, Rudner DZ. 2007. The ATPase SpoIIIE transports DNA across fused septal membranes during sporulation in Bacillus subtilis. Cell 131: 1301-1312.

Cascales E, Christie PJ. 2004. Definition of a bacterial type IV secretion pathway for a DNA substrate. Science 304: $1170-1173$.

Chandran V, Fronzes R, Duquerroy S, Cronin N, Navaza J, Waksman G. 2009. Structure of the outer membrane complex of a type IV secretion system. Nature 462: 1011-1015.

Chen I, Dubnau D. 2004. DNA uptake during bacterial transformation. Nat Rev Microbiol 2: 241-249.

Chen I, Christie PJ, Dubnau D. 2005. The ins and outs of DNA transfer in bacteria. Science 310: 1456-1460.

Chen I, Provvedi R, Dubnau D. 2006. A macromolecular complex formed by a pilin-like protein in competent Bacillus subtilis. J Biol Chem 281: 21720-21727.

Chiang P, Sampaleanu LM, Ayers M, Pahuta M, Howell PL, Burrows LL. 2008. Functional role of conserved residues in the characteristic secretion NTPase motifs of the Pseudomonas aeruginosa type IV pilus motor proteins PilB, PilT and PilU. Microbiology 154: 114-126.

Christie PJ. 1997. Agrobacterium tumefaciens T-complex transport apparatus: A paradigm for a new family of multifunctional transporters in eubacteria. $J$ Bacteriol 179: 3085-3094.

Christie PJ. 2009. Structural biology: Translocation chamber's secrets. Nature 462: 992-994.

Christie PJ, Atmakuri K, Krishnamoorthy V, Jakubowski S, Cascales E. 2005. Biogenesis, architecture, and function of bacterial type IV secretion systems. Annu Rev Microbiol 59: $451-485$.

Chung YS, Breidt F, Dubnau D. 1998. Cell surface localization and processing of the ComG proteins, required for DNA binding during transformation of Bacillus subtilis. Mol Microbiol 29: 905-913.

Clausen M, Koomey M, Maier B. 2009b. Dynamics of type IV pili is controlled by switching between multiple states. Biophys J 96: 1169-1177.

Clausen M, Jakovljevic V, Sogaard-Andersen L, Maier B, 2009a. High-force generation is a conserved property of type IV pilus systems. J Bacteriol 191: 4633-4638.

Claverys JP, Lacks SA. 1986. Heteroduplex deoxyribonucleic acid base mismatch repair in bacteria. Microbiol Rev 50: $133-165$.

Claverys JP, Martin B, Polard P. 2009. The genetic transformation machinery: Composition, localization, and mechanism. FEMS Microbiol Rev 33: 643-656.

Claverys JP, Prudhomme M, Martin B. 2006. Induction of competence regulons as a general response to stress in gram-positive bacteria. Annu Rev Microbiol 60: 451-475.

Collins RF, Frye SA, Kitmitto A, Ford RC, Tonjum T, Derrick JP. 2004. Structure of the Neisseria meningitidis outer membrane PilQ secretin complex at 12 A resolution. J Biol Chem 279: 39750-39756.
Membrane-associated DNA Transport Machines

Craig L, Pique ME, Tainer JA. 2004. Type IV pilus structure and bacterial pathogenicity. Nat Rev Microbiol 2: 363-378.

Danner DB, Deich RA, Sisco KL, Smith HO. 1980. An eleven-base-pair sequence determines the specificity of DNA uptake in Haemophilus transformation. Gene 11: 311-318.

Dedrick RM, Wildschutte H, McCormick JR. 2009. Genetic interactions of smc, $\mathrm{ftsK}$, and parB genes in Streptomyces coelicolor and their developmental genome segregation phenotypes. J Bacteriol 191: 320-332.

Di Lallo G, Fagioli M, Barionovi D, Ghelardini P, Paolozzi L. 2003. Use of a two-hybrid assay to study the assembly of a complex multicomponent protein machinery: Bacterial septosome differentiation. Microbiology 149: 3353-3359.

Draper GC, McLennan N, Begg K, Masters M, Donachie WD. 1998. Only the N-terminal domain of FtsK functions in cell division. J Bacteriol 180: 4621-4627.

Draskovic I, Dubnau D. 2005. Biogenesis of a putative channel protein, ComEC, required for DNA uptake: Membrane topology, oligomerization and formation of disulphide bonds. Mol Microbiol 55: 881-896.

Dubnau D. 1999. DNA uptake in bacteria. Annu Rev Microbiol 53: 217-244.

Elkins C, Thomas CE, Seifert HS, Sparling PF 1991 Species-specific uptake of DNA by gonococci is mediated by a 10-base- pair sequence. J Bacteriol 173: 3911-3913.

Forest KT, Tainer JA. 1997. Type-4 pilus-structure: Outside to inside and top to bottom-a minireview. Gene 192: $165-169$.

Foulger D, Errington J. 1989. The role of the sporulation gene spoIIIE in the regulation of prespore-specific gene expression in Bacillus subtilis. Mol Microbiol 3: 1247-1255.

Friedrich A, Prust C, Hartsch T, Henne A, Averhoff B. 2002. Molecular analyses of the natural transformation machinery and identification of pilus structures in the extremely thermophilic bacterium Thermus thermophilus strain HB27. Appl Environ Microbiol 68: 745-755.

Fronzes R, Christie PJ, Waksman G. 2009a. The structural biology of type IV secretion systems. Nat Rev Microbiol 7: 703-714.

Fronzes R, Schafer E, Wang L, Saibil HR, Orlova EV, Waksman G. 2009b. Structure of a type IV secretion system core complex. Science 323: 266-268.

Gomis-Ruth FX, Coll M. 2006. Cut and move: Protein machinery for DNA processing in bacterial conjugation. Curr Opin Struct Biol 16: 744-752.

Gomis-Ruth FX, Moncalian G, Perez-Luque R, Gonzalez A, Cabezon E, de la Cruz F, Coll M. 2001. The bacterial conjugation protein $\operatorname{TrwB}$ resembles ring helicases and F1-ATPase. Nature 409: 637-641.

Hahn J, Kramer N, Briley KJr, Dubnau D. 2009. McsA and B mediate the delocalization of competence proteins from the cell poles of Bacillus subtilis. Mol Microbiol 72: 202-215.

Hahn J, Maier B, Haijema BJ, Sheetz M, Dubnau D. 2005. Transformation proteins and DNA uptake localize to the cell poles in Bacillus subtilis. Cell 122: 59-71. 


\section{B. Burton and D. Dubnau}

Hamilton HL, Dillard JP. 2006. Natural transformation of Neisseria gonorrhoeae: from DNA donation to homologous recombination. Mol Microbiol 59: 376-385.

Hamoen LW, Venema G, Kuipers OP. 2003. Controlling competence in Bacillus subtilis: Shared use of regulators. Microbiology 149: 9-17.

Herdendorf TJ, McCaslin DR, Forest KT. 2002. Aquifex aeolicus PilT, homologue of a surface motility protein, is a thermostable oligomeric NTPase. J Bacteriol 184: 6465-6471.

Hobbs M, Mattick JS. 1993. Common components in the assembly of type-4 fimbriae DNA transfer systems, filamentous phage and protein secretion apparatus; a general system for the formation of surface-associated protein complexes. Mol Microbiol 10: 233-243.

Hofreuter D, Odenbreit S, Puls J, Schwan D, Haas R. 2000. Genetic competence in Helicobacter pylori: Mechanisms and biological implications. Res Microbiol 151: $487-491$.

Inamine GS, Dubnau D. 1995. ComEA, a Bacillus subtilis integral membrane protein required for genetic transformation, is needed for both DNA binding and transport. J Bacteriol 177: 3045-3051.

Iyer LM, Makarova KS, Koonin EV, Aravind L. 2004. Comparative genomics of the FtsK-HerA superfamily of pumping ATPases: Implications for the origins of chromosome segregation, cell division and viral capsid packaging. Nucleic Acids Res 32: 5260-5279.

Jakovljevic V, Leonardy S, Hoppert M, Sogaard-Andersen L 2008. PilB and PilT are ATPases acting antagonistically in type IV pilus function in Myxococcus xanthus. J Bacteriol 190: $2411-2421$

Johnson TL, Abendroth J, Hol WG, Sandkvist M. 2006. Type II secretion: From structure to function. FEMS Microbiol Lett 255: 175-186.

Judd PK, Kumar RB, Das A. 2005. Spatial location and requirements for the assembly of the Agrobacterium tumefaciens type IV secretion apparatus. Proc Natl Acad Sci 102: 11498-11503.

Kaimer C, Gonzalez-Pastor JE, Graumann PL. 2009. SpoIIIE and a novel type of DNA translocase, SftA, couple chromosome segregation with cell division in Bacillus subtilis. Mol Microbiol 74: 810-825.

Karnholz A, Hoefler C, Odenbreit S, Fischer W, Hofreuter D, Haas R. 2006. Functional and topological characterization of novel components of the comB DNA transformation competence system in Helicobacter pylori. J Bacteriol 188: $882-893$

Kidane D, Graumann PL. 2005. Intracellular protein and DNA dynamics in competent Bacillus subtilis cells. Cell 122: $73-84$.

Kirstein J, Dougan DA, Gerth U, Hecker M, Turgay K. 2007. The tyrosine kinase McsB is a regulated adaptor protein for ClpCP. EMBO J 26: 2061-2070.

Kohler R, Schafer K, Muller S, Vignon G, Diederichs K, Philippsen A, Ringler P, Pugsley AP, Engel A, Welte W. 2004. Structure and assembly of the pseudopilin PulG. Mol Microbiol 54: 647-664.

Kramer N, Hahn J, Dubnau D. 2007. Multiple interactions among the competence proteins of Bacillus subtilis. Mol Microbiol 65: 454-464.
Lacks S, Greenberg B, Neuberger M. 1974. Role of a deoxyribonuclease in the genetic transformation of Diplococcus pneumoniae. Proc Natl Acad Sci 71: 2305-2309.

Le Bourgeois P, Bugarel M, Campo N, Daveran-Mingot ML, Labonte J, Lanfranchi D, Lautier T, Pages C, Ritzenthaler P. 2007. The unconventional Xer recombination machinery of Streptococci/Lactococci. PLoS Genet 3: el17.

Leisner M, Stingl K, Frey E, Maier B. 2008. Stochastic switching to competence. Curr Opin Microbiol 11: 553-559.

Levy O, Ptacin JL, Pease PJ, Gore J, Eisen MB, Bustamante C, Cozzarelli NR. 2005. Identification of oligonucleotide sequences that direct the movement of the Escherichia coli FtsK translocase. Proc Natl Acad Sci 102: 17618-17623.

Londono-Vallejo JA, Dubnau D. 1994. Mutation of the putative nucleotide binding site of the Bacillus subtilis membrane protein ComFA abolishes the uptake of DNA during transformation. J Bacteriol 176: 4642-4645.

Lowe J, Ellonen A, Allen MD, Atkinson C, Sherratt DJ, Grainge I. 2008. Molecular mechanism of sequencedirected DNA loading and translocation by FtsK. Mol Cell 31: 498-509.

Macfadyen LP. 2000. Regulation of competence development in Haemophilus influenzae. J Theor Biol 207: 349-359.

Maier B, Chen I, Dubnau D, Sheetz MP. 2004. DNA transport into Bacillus subtilis requires proton motive force to generate large molecular forces. Nat Struct Mol Biol 11: 643-649.

Maier B, Potter L, So M, Long CD, Seifert HS, Sheetz MP. 2002. Single pilus motor forces exceed 100 pN. Proc Natl Acad Sci 99: 16012-16017.

Majewski J, Cohan FM. 1998. The effect of mismatch repair and heteroduplex formation on sexual isolation in Bacillus. Genetics 148: 13-18.

Mandlik A, Swierczynski A, Das A, Ton-That H. 2008. Pili in Gram-positive bacteria: Assembly, involvement in colonization and biofilm development. Trends Microbiol 16: $33-40$.

Marquis KA, Burton BM, Nollmann M, Ptacin JL, Bustamante C, Ben-Yehuda S, Rudner DZ. 2008. SpoIIIE strips proteins off the DNA during chromosome translocation. Genes Dev 22: 1786-1795.

Massey TH, Mercogliano CP, Yates J, Sherratt DJ, Lowe J. 2006. Double-stranded DNA translocation: Structure and mechanism of hexameric FtsK. Mol Cell 23: 457-469.

Mattick JS. 2002. Type iv pili and twitching motility. Annu Rev Microbiol 56: 289-314.

Méjean V, Claverys J. 1988. Polarity of DNA entry in transformation of Streptococcus pneumoniae. Mol Gen Genet 213: 444-448.

Mejean V, Claverys JP. 1993. DNA processing during entry in transformation of Streptococcus pneumoniae. J Biol Chem 268: $5594-5599$.

Merz AJ, So M, Sheetz MP. 2000. Pilus retraction powers bacterial twitching motility. Nature 407: 98-102.

Mortier-Barriere I, Velten M, Dupaigne P, Mirouze N, Pietrement O, McGovern S, Fichant G, Martin B, Noirot 
P, Le Cam, et al. 2007. A key presynaptic role in transformation for a widespread bacterial protein: DprA conveys incoming ssDNA to RecA. Cell 130: 824-836.

Panicker MM, Minkley EGJr. 1985. DNA transfer occurs during a cell surface contact stage of $F$ sex factor-mediated bacterial conjugation. J Bacteriol 162: 584-590.

Pease PJ, Levy O, Cost GJ, Gore J, Ptacin JL, Sherratt D, Bustamante C, Cozzarelli NR. 2005. Sequence-directed DNA translocation by purified FtsK. Science 307: 586-590.

Proft T, Baker EN. 2009. Pili in Gram-negative and Grampositive bacteria-structure, assembly and their role in disease. Cell Mol Life Sci 66: 613-635.

Provvedi R, Dubnau D. 1999. ComEA is a DNA receptor for transformation of competent Bacillus subtilis. Mol Microbiol 31: 271-280.

Provvedi R, Chen I, Dubnau D. 2001. NucA is required for DNA cleavage during transformation of Bacillus subtilis. Mol Microbiol 40: 634-644.

Ptacin JL, Nollmann M, Becker EC, Cozzarelli NR, Pogliano K, Bustamante C. 2008. Sequence-directed DNA export guides chromosome translocation during sporulation in Bacillus subtilis. Nat Struct Mol Biol 15: 485-493.

Ptacin JL, Nollmann M, Bustamante C, Cozzarelli NR. 2006 Identification of the FtsK sequence-recognition domain. Nat Struct Mol Biol 13: 1023-1025.

Saleh OA, Perals C, Barre FX, Allemand JF. 2004. Fast DNAsequence independent translocation by FtsK in a singlemolecule experiment. Embo J 23: 2430-2439.

Sauvonnet N, Vignon G, Pugsley AP, Gounon P. 2000. Pilus formation and protein secretion by the same machinery in Escherichia coli. Embo J 19: 2221-2228.

Sharp MD, Pogliano K. 1999. An in vivo membrane fusion assay implicates SpoIIIE in the final stages of engulfment during Bacillus subtilis sporulation. Proc Natl Acad Sci 96: 14553-14558.

Sharp MD, Pogliano K. 2002a. MinCD-dependent regulation of the polarity of SpoIIIE assembly and DNA transfer. Embo J 21: 6267-6274.

Sharp MD, Pogliano K. 2002b. Role of cell-specific SpoIIIE assembly in polarity of DNA transfer. Science 295: 137-139.

Sharp MD, Pogliano K. 2003. The membrane domain of SpoIIIE is required for membrane fusion during Bacillus subtilis sporulation. J Bacteriol 185: 2005-2008.

Shu AC, Wu CC, Chen YY, Peng HL, Chang HY, Yew TR. 2008. Evidence of DNA transfer through F-pilus channels during Escherichia coli conjugation. Langmuir 24: 6796-6802.

Singleton MR, Dillingham MS, Wigley DB. 2007. Structure and mechanism of helicases and nucleic acid translocases. Annu Rev Biochem 76: 23-50.

Sivanathan V, Allen MD, de Bekker C, Baker R, Arciszewska LK, Freund SM, Bycroft M, Lowe J, Sherratt DJ. 2006. The FtsK $\gamma$ domain directs oriented DNA translocation by interacting with KOPS. Nat Struct Mol Biol 13: 965-972.

Skerker JM, Berg HC. 2001. Direct observation of extension and retraction of type IV pili. Proc Natl Acad Sci 98: 6901-6904.
Membrane-associated DNA Transport Machines

Smeets LC, Bijlsma JJ, Kuipers EJ, Vandenbroucke-Grauls CM, Kusters JG. 2000. The dprA gene is required for natural transformation of Helicobacter pylori. FEMS Immunol Med Microbiol 27: 99-102.

Stingl K, Muller S, Scheidgen-Kleyboldt G, Clausen M, Maier B. 2010. Composite system mediates two-step DNA uptake into Helicobacter pylori. Proc Natl Acad Sci 107: 1184-1189.

Tadesse S, Graumann PL. 2007. DprA/Smf protein localizes at the DNA uptake machinery in competent Bacillus subtilis cells. BMC Microbiol 7: 105.

Tato I, Zunzunegui S, de la Cruz F, Cabezon E. 2005. TrwB, the coupling protein involved in DNA transport during bacterial conjugation, is a DNA-dependent ATPase. Proc Natl Acad Sci 102: 8156-8161.

Teng WL, Bannam TL, Parsons JA, Rood JI. 2008. Functional characterization and localization of the TcpH conjugation protein from Clostridium perfringens. J Bacteriol 190: $5075-5086$

Terradot L, Bayliss R, Oomen C, Leonard GA, Baron C, Waksman G. 2005. Structures of two core subunits of the bacterial type IV secretion system, VirB8 from Brucella suis and ComB10 from Helicobacter pylori. Proc Natl Acad Sci 102: 4596-4601.

Thanbichler M. 2009. Synchronization of chromosome dynamics and cell division in bacteria. Cold Spring Harb Perspect Biol 1: 000331.

Tomb J-F, El-Hajj H, Smith HO. 1991. Nucleotide sequence of a cluster of genes involved in the transformation of Haemophilus influenzae RD. Gene 104: 1-10.

Vagner V, Claverys J-P, Ehrlich SD, Méjean V. 1990. Direction of DNA entry in competent cells of Bacillus subtilis. Mol Microbiol 4: 1785-1788.

Val ME, Kennedy SP, El Karoui M, Bonne L, Chevalier F, Barre FX. 2008. FtsK-dependent dimer resolution on multiple chromosomes in the pathogen Vibrio cholerae. PLoS Genet 4: e1000201.

van Nieuwenhoven MH, Hellingwerf KJ, Venema G, Konings WN. 1982. Role of proton motive force in genetic transformation of Bacillus subtilis. J Bacteriol 151: $771-776$.

Wang L, Lutkenhaus J. 1998. FtsK is an essential cell division protein that is localized to the septum and induced as part of the SOS response. Mol Microbiol 29: 731-740.

Wang SC, West L, Shapiro L. 2006. The bifunctional FtsK protein mediates chromosome partitioning and cell division in Caulobacter. J Bacteriol 188: 1497-1508.

Wang L, Yu Y, He X, Zhou X, Deng Z, Chater KF, Tao M. 2007. Role of an FtsK-like protein in genetic stability in Streptomyces coelicolor A3(2). J Bacteriol 189: 2310-2318.

Wu LJ, Errington J. 1994. Bacillus subtilis spoIIIE protein required for DNA segregation during asymmetric cell division. Science 264: 572-575.

Wu LJ, Errington J. 1997. Septal localization of the SpoIIIE chromosome partitioning protein in Bacillus subtilis. Embo J 16: 2161-2169.

Wu LJ, Errington J. 1998. Use of asymmetric cell division and spoIIIE mutants to probe chromosome orientation 


\section{B. Burton and D. Dubnau}

and organization in Bacillus subtilis. Mol Microbiol 27: 777-786.

Yeh YC, Lin TL, Chang KC, Wang JT. 2003. Characterization of a ComE3 homologue essential for DNA transformation in Helicobacter pylori. Infect Immun 71: 5427-5431.

Yeo HJ, Savvides SN, Herr AB, Lanka E, Waksman G. 2000. Crystal structure of the hexameric traffic ATPase of the Helicobacter pylori type IV secretion system. Mol Cell 6: $1461-1472$.
Yeo HJ, Yuan Q, Beck MR, Baron C, Waksman G. 2003. Structural and functional characterization of the VirB5 protein from the type IV secretion system encoded by the conjugative plasmid pKM101. Proc Natl Acad Sci 100: 15947-15952.

Yu XC, Tran AH, Sun Q, Margolin W. 1998. Localization of cell division protein FtsK to the Escherichia coli septum and identification of a potential $\mathrm{N}$-terminal targeting domain. J Bacteriol 180: 1296-1304. 


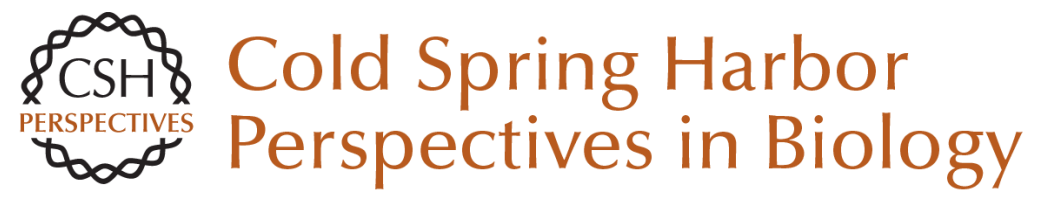

\section{Membrane-associated DNA Transport Machines}

Briana Burton and David Dubnau

Cold Spring Harb Perspect Biol 2010; doi: 10.1101/cshperspect.a000406 originally published online June 23, 2010

\section{Subject Collection Cell Biology of Bacteria}

\section{Electron Cryotomography}

Elitza I. Tocheva, Zhuo Li and Grant J. Jensen

Protein Subcellular Localization in Bacteria David Z. Rudner and Richard Losick

Poles Apart: Prokaryotic Polar Organelles and Their Spatial Regulation

Clare L. Kirkpatrick and Patrick H. Viollier

Myxobacteria, Polarity, and Multicellular

Morphogenesis

Dale Kaiser, Mark Robinson and Lee Kroos

Membrane-associated DNA Transport Machines

Briana Burton and David Dubnau

The Bacterial Cell Envelope

Thomas J. Silhavy, Daniel Kahne and Suzanne Walker

Cell Biology of Prokaryotic Organelles Dorothee Murat, Meghan Byrne and Arash Komeili

Bacterial Chromosome Organization and

\section{Segregation}

Esteban Toro and Lucy Shapiro
Cyanobacterial Heterocysts
Krithika Kumar, Rodrigo A. Mella-Herrera and
James W. Golden

Synchronization of Chromosome Dynamics and

Cell Division in Bacteria Martin Thanbichler

Automated Quantitative Live Cell Fluorescence

Microscopy

Michael Fero and Kit Pogliano

The Structure and Function of Bacterial Actin

Homologs Joshua W. Shaevitz and Zemer Gitai

\section{Biofilms}

Daniel López, Hera Vlamakis and Roberto Kolter

Bacterial Nanomachines: The Flagellum and Type

III Injectisome

Marc Erhardt, Keiichi Namba and Kelly T. Hughes

Single-Molecule and Superresolution Imaging in Live Bacteria Cells Julie S. Biteen and W.E. Moerner

For additional articles in this collection, see http://cshperspectives.cshlp.org/cgi/collection/

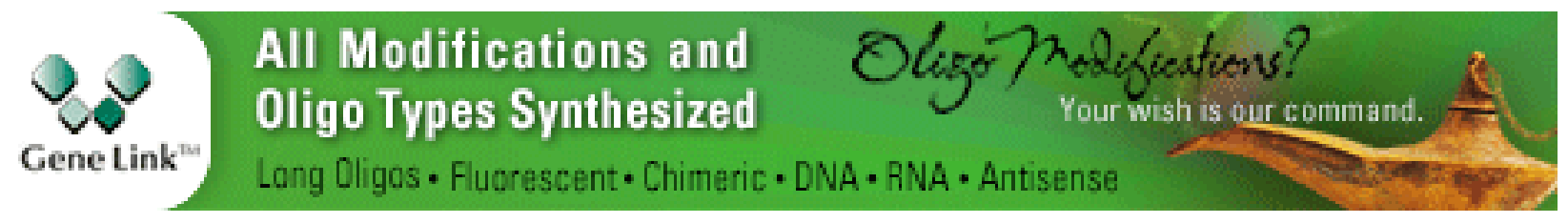

Copyright @ 2010 Cold Spring Harbor Laboratory Press; all rights reserved 